\title{
COMPUTERISED AXIAL TOMOGRAPHY FOR TIBIAL PLATEAU FRACTURES
}

\author{
J. J. DIAS, A. J. STIRLING, D. B. L. FINLAY, P. J. GREGG
}

From the Leicester Royal Infirmary

\begin{abstract}
Sixteen consecutive patients with tibial plateau fractures were investigated by standard radiography, biplanar tomography and computerised axial tomograms (CT scans). It was found that CT scanning proved most helpful for classifying the type of fracture, for evaluating the degree of comminution, and for measuring displacement. Moreover, because a single position was maintained throughout the investigation, the patients felt less discomfort than during other assessment procedures. For these reasons $\mathrm{CT}$ scanning is recommended for evaluating this type of fracture.
\end{abstract}

Accurate reduction and stable internal fixation followed by early mobilisation is regarded by many as the appropriate treatment for displaced fractures of the tibial plateau (Rombold 1960; Rasmussen 1973). The merit of this policy is outside the scope of this paper, but for optimum pre-operative planning-and to avoid unnecessary operations on fractures that are beyond reconstruction-the fracture type, the extent of displacement and especially the degree of comminution of both the tibial plateau and its supporting cortex require accurate definition.

Standard radiographs are often inaccurate. They underestimate the degree of displacement, significant depressions may be missed, and the exact location and extent of the fracture as well as the degree of communition are difficult to evaluate. In 1974 Moore and Harvey proposed a $105^{\circ}$ view of the tibial plateau; these oblique radiographs provided more information about the type of fracture and allowed a better estimation of the depression. Biplanar tomography, which provided improved sagittal and coronal perspectives, was subsequently reported as a more accurate method of assessing these fractures (Elstrom et al. 1976). This investigation, however, does have certain drawbacks: the splints have to be removed and adequate analgesia given because the patient and the limb must often be moved between anteroposterior and lateral tomograms. A magnification

J. J. Dias, FRCS, Lecturer

D. B. L. Finlay, MRCP, FRCR, Consultant Radiologist

P. J. Gregg, MD, FRCS, Professor of Orthopaedic Surgery

University of Leicester School of Medicine, Department of Orthopaedic Surgery, Glenfield General Hospital, Groby Road, Leicester LE3 $9 Q P$, England.

A. J. Stirling, FRCS, Research Fellow

University Department of Orthopaedic Surgery, Clinical Sciences Building, Level 8, St James's University Hospital, Leeds LS9 7TF, England.

Requests for reprints should be sent to Professor P. J. Gregg.

(C) 1987 British Editorial Society of Bone and Joint Surgery $0301-620 \mathrm{X} / 87 / 1012 \$ 2.00$ factor of approximately $15 \%$ must also be taken into account in all measurements. By contrast, CT scanning reveals the hitherto unseen transverse plane and, because this method of assessing tibial plateau fractures had not been previously reported, a prospective study comparing plain radiography, biplanar tomography and computerised axial tomography was conducted to determine the most advantageous method of evaluation.

\section{PATIENTS AND METHODS}

Sixteen consecutive patients with tibial plateau fractures were available for study (four women and $12 \mathrm{men}$ ); patients with undisplaced fractures were excluded.

On initial presentation standard anteroposterior and lateral radiographs were obtained; the 16 displaced fractures were then also studied by biplanar and computerised tomography. An average of 15 biplanar tomograms were taken for each patient, using the method of Elstrom et al. (1976); these were presented on single radiographic plates or in composites of two or four per plate, and needed to be arranged and viewed in sequence. The first CT section (using an International General Electronic CT scanner 80/800) was taken at the level of the femoral condyles and the next section taken at the level of the non-fractured plateau or at the base of the tibial spine (Fig. 1); an average of four additional sections were taken to include the whole extent of the fracture distally. These CT sections were all presented on a single composite film in sequence, making review easier and less time-consuming.

The standard radiographs, tomograms and CT scans were viewed independently. On each, the fracture was classified according to our modification of Duparc and Ficat's criteria (1960) (Table I) (Fig. 2); the extent of the plateau involved in the fracture was outlined, the degree of comminution was noted, and the magnitude of 


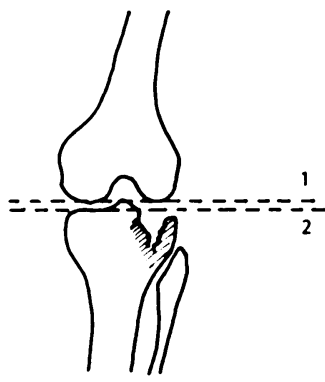

Fig. 1

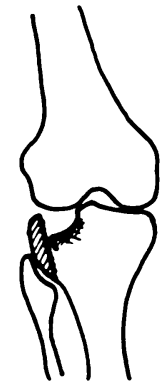

Type 1

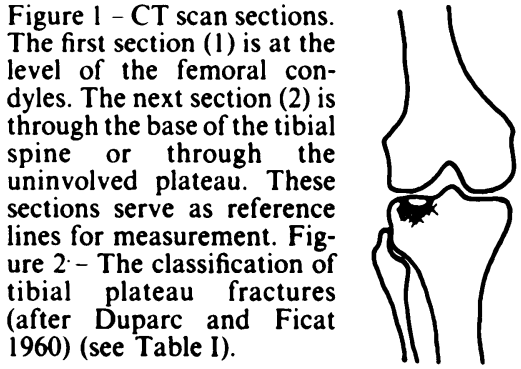

Type III

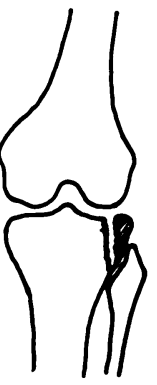

Type 11

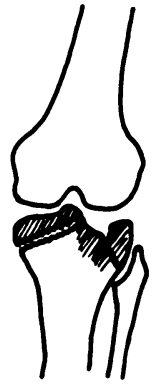

Type IV
Fig. 2

displacement was measured in millimetres. Using each method, we tried to determine whether the anterior aspect of the tibial cortex was intact and, if not, whether the fracture line(s) could be used as a route to elevate a depressed fragment without an additional window. We also tried to judge the degree of comminution to
Table I. Classification of fractures of the tibial plateau (modified from Duparc and Ficat 1960)

Type 1 Mixed (the plateau is depressed and split):

$\begin{array}{ll}\text { a. } & \text { Anterior } \\ \text { b. } & \text { Posterior } \\ \text { c. } & \text { Total surface } \\ \text { d. } & \text { Marginal } \\ \text { e. } & \text { Central }\end{array}$

Type 2 Split only:

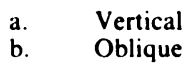

Type 3 Depressed only:

$\begin{array}{ll}\text { a. } & \text { Anterior } \\ \text { b. } & \text { Posterior } \\ \text { c. } & \text { Total surface } \\ \text { d. } & \text { Marginal } \\ \text { e. } & \text { Central }\end{array}$

Type 4 Both plateaux involved:

$$
\begin{array}{ll}
\text { a. } & \text { Simple } \\
\text { b. } & \text { Complex } \\
\text { c. } & \text { Comminuted }
\end{array}
$$

determine if open reduction and internal fixation would be worthwhile.

\section{RESULTS}

Of the 16 tibial plateau fractures studied, the lateral plateau was involved in 10 , both the medial and lateral plateau in three, and only the medial plateau in the remaining three.

Classification. After assessment by biplanar tomography

\begin{tabular}{|c|c|c|c|c|c|c|c|c|c|c|}
\hline \multirow[b]{2}{*}{ Case } & \multicolumn{3}{|c|}{ Type of fracture } & \multicolumn{3}{|c|}{ Extent of fracture (millimetres) } & \multicolumn{3}{|c|}{ Depression (millimetres) } & \multirow{2}{*}{$\begin{array}{l}\text { Angular } \\
\text { displacement }\end{array}$} \\
\hline & Radiographs & Tomograms & CT scans & Radiographs & Tomograms & CT scans & Radiographs & Tomograms & $C T$ scans & \\
\hline 1 & $1 ?$ & la & la & 4 & 6 & 5 & 21 & 22 & 17 & \\
\hline 2 & $2 \mathrm{a}$ & $2 \mathrm{a}$ & la & 2 & 2 & 1.5 & 0 & 2 & 5 & \\
\hline 3 & $2 b$ & $2 b$ & $2 b$ & 4 & 9 & 6 & - & - & - & $12^{\circ}$ \\
\hline 4 & $2 b$ & $4 a$ & $4 \mathrm{a}$ & 7 & 7 & 10 & - & - & - & \\
\hline 5 & $2 \mathrm{a}$ & $2 \mathrm{a}$ & $2 \mathrm{a}$ & 3 & 4 & 2 & - & - &.- & $16^{\circ}$ \\
\hline 6 & $2 \mathrm{a}$ & lc & la & 1 & 3 & 4 & 0 & 9 & 6 & \\
\hline 7 & Ic & lc & lc & 2 & 9 & 7 & 12 & 17 & 20 & \\
\hline 8 & $1 b$ & lc & Ic & 7 & 6 & 8 & 26 & 28 & 21.5 & \\
\hline 9 & $4 a$ & $4 b$ & $4 \mathrm{c}$ & 10 & 9 & 6 & 12 & 12 & 8 & \\
\hline 10 & $3 d$ & lc & $1 \mathrm{c}$ & - & 6 & 4 & 20 & 21 & 15.5 & \\
\hline 11 & $3 e$ & le & lc & - & 8 & 5 & 27 & 32 & 23 & \\
\hline 12 & $1 ?$ & la & la & 6 & 6 & 4 & 21 & 20 & 15 & \\
\hline 13 & $2 a$ & le & Ic & 6 & 8 & 4 & - & 10 & 8 & \\
\hline 14 & $1 ?$ & la & $1 \mathrm{a}$ & 3 & 9 & 6 & 10 & 7 & 5.5 & \\
\hline 15 & $2 a$ & $2 b$ & $2 b$ & 2 & 4 & 3 & - & - & - & $9^{\circ}$ \\
\hline 16 & $4 a$ & $4 b$ & $4 b$ & 4 & 8 & 6 & 0 & 6 & 12.5 & \\
\hline
\end{tabular}
and CT scanning, three fractures which had been

Table II. Summary of findings for each patient 


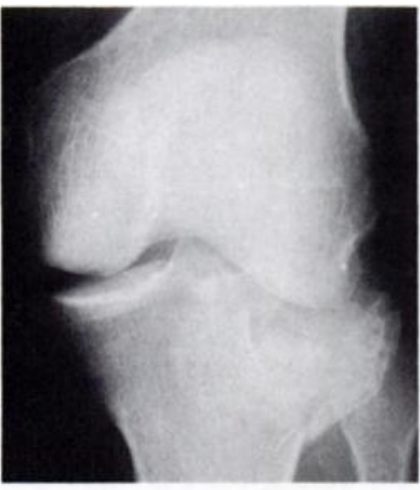

Fig. 3

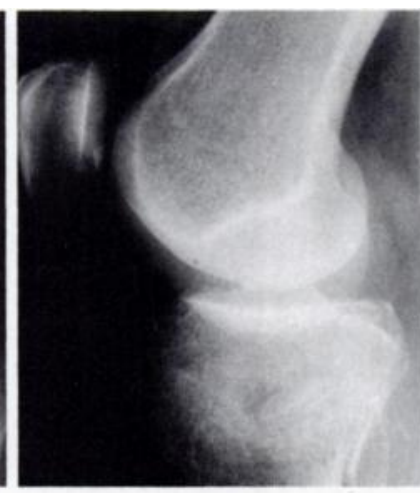

Fig. 4

Figures 3 and 4 - Anteroposterior and lateral plain radiographs of the injured left knee in a patient with a Type 1 fracture: the extent of tibial plateau involvement is unclear, there is no obvious gap and the cortex does not appear to be comminuted. Figures 5 to 8 - Tomograms of the same fracture in the anteroposterior plane allow for more accurate assessment. When evaluated in sequence they give more information about the extent of plateau involvement (the plaster backslab had been removed for this investigation). Figures 9 to 12 - Transverse CT sections of the fracture. Figure 9 - A section at the level of the normal medial plateau, taken through the plaster cast. The dark area in the lateral plateau demonstrates the exact site and extent of the depressed segment. There is a gap in the front through which fragments could be elevated. The outer rim is clearly shown to be split. Figure 10 - The next section passes through the depressed fragments; these show as a circular white area around the centre of the depression. The parameters of the CT scan give the exact depth of each section. Figures 11 and $12-$ Lower sections demonstrate not only the extent of cortical comminution but also its exact site: the posterior extension of the fracture, not obvious on radiographs or tomograms, is clearly demonstrated.

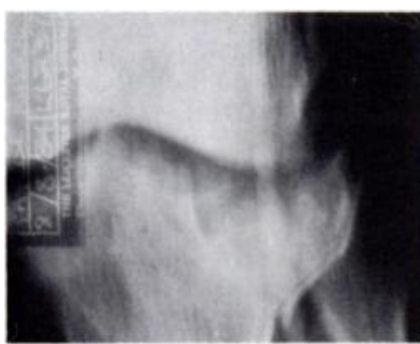

Fig. 5

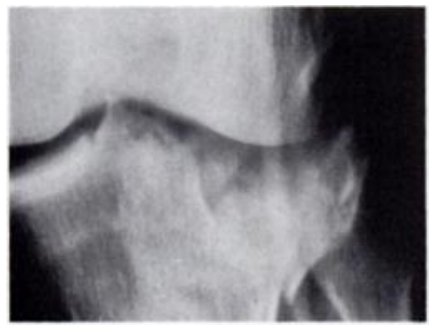

Fig. 7

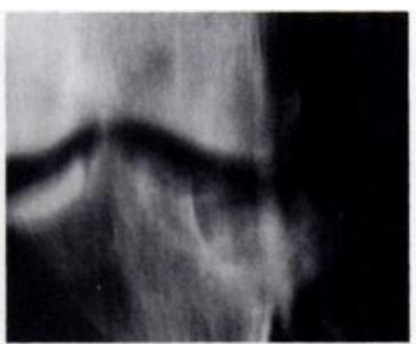

Fig. 6

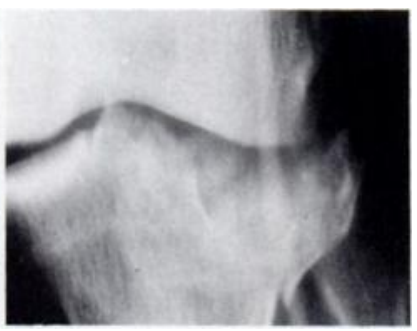

Fig. 8

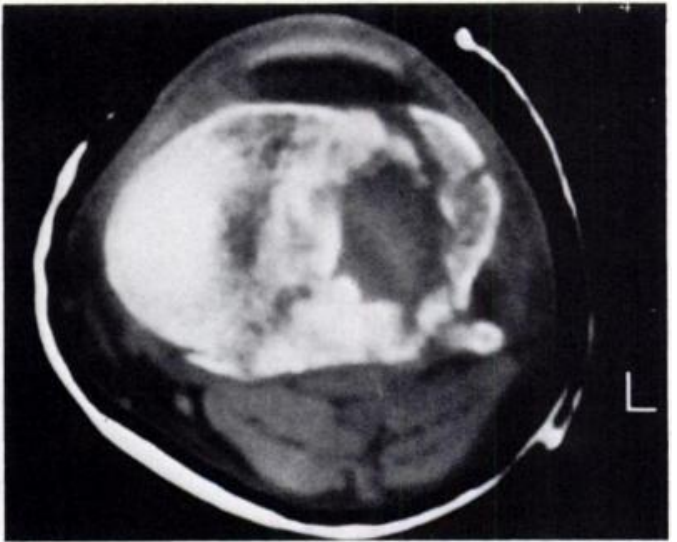

Fig. 9

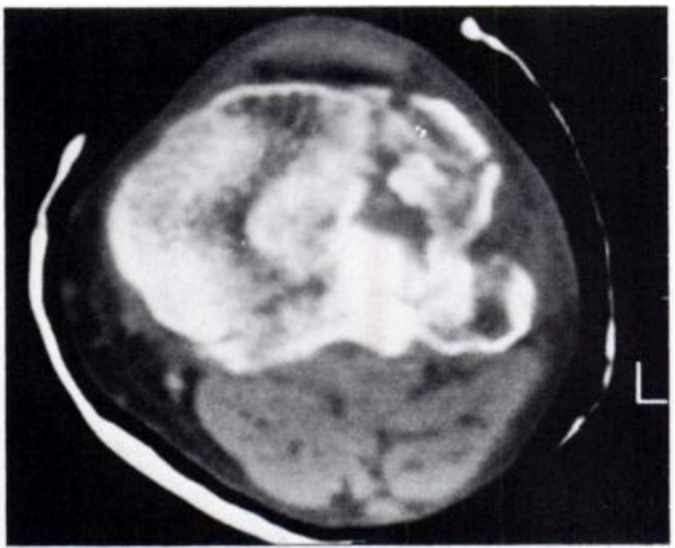

Fig. 10

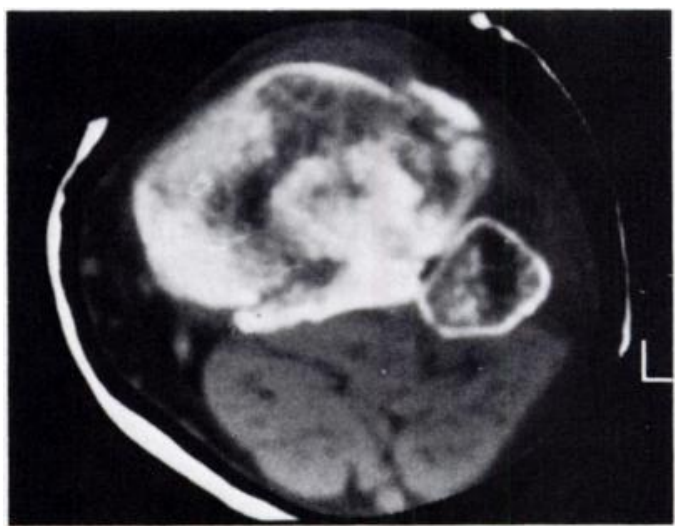

Fig. 11

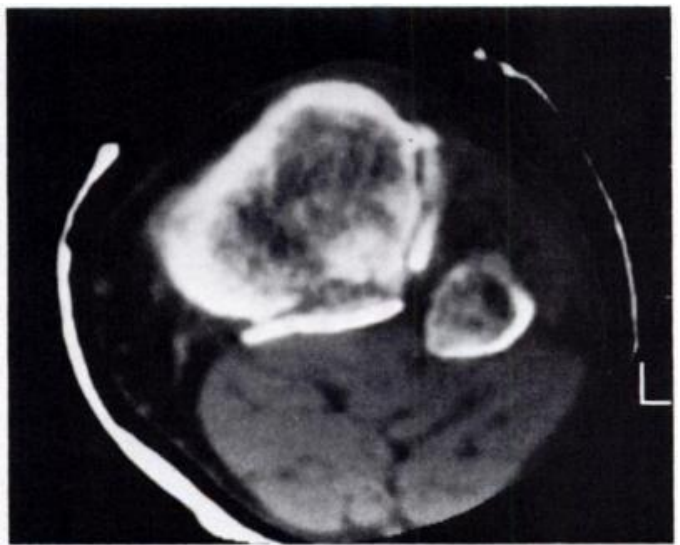

Fig. 12 
Table III. Comminution of the fracture assessed by different methods

\begin{tabular}{lclll}
\hline & None & Mild & Moderate & Severe \\
\hline Plain radiology & 11 & 4 & 1 & - \\
Biplanar tomography & 8 & 5 & 3 & - \\
CT scanning & 3 & 8 & 3 & 2 \\
\hline
\end{tabular}

difficult to classify by plain radiography, three initially classified as Type 2 and two as Type 3 were all reclassified as Type 1 (Figs 3 and 4). Moreover, one of these Type 2 fractures had been classified as such by both radiography and biplanar tomography (Table II). The transverse sections of the CT scans provided better views not only of the fracture itself but of the exact site and extent of the tibial plateau involvment; this had been more difficult to see on biplanar tomograms.

Comminution. On plain radiographs 11 of the 16 fractures showed no comminution of the tibial cortex, four had mild (that is, surgically unimportant) comminution and one had moderate comminution (treatable by operation) (Table III). By contrast, biplanar tomograms and CT scans revealed many more fractures with moderate comminution (Figs 5 to 12). Two fractures, when viewed on plain radiographs and biplanar tomograms, had been considered for operative reconstruction; however, CT scans revealed comminution so severe as to preclude operative reconstruction. The CT scans clearly demonstrated both the degree of comminution and the orientation of the fragments.

Displacement. On plain radiographs and biplanar tomograms the displacement of the depressed fragment was measured in millimetres from the level of the intact tibial plateau or from the base of the tibial spine in the anteroposterior and lateral projections (Table IV). On each CT section the gàntry level in millimetres was noted on the film, and a simple subtraction of the level of the depressed fragment from that of the tibial plateau provided the measurement. The widest area of displacement of the split fragment was also noted on the three different types of film (Table IV).

It was found that plain radiographs clearly underestimated the extent of displacement, while measurement from CT scans matched those of tomograms only if the latter had been corrected for an approximate magnification of $15 \%$ as suggested by Elstrom et al. (1976).

\section{DISCUSSION}

Fractures of the tibial plateau are notoriously difficult to assess, especially when trying to decide whether to operate. Rasmussen (1973) considered a valgus or varus instability of more than $10^{\circ}$ in the fully extended knee to be an indication for operative reconstruction. Hohl (1967) and Rombold (1960), however, suggested that a
Table IV. Average measurement of displacement by different methods

\begin{tabular}{lll}
\hline & $\begin{array}{l}\text { Split fragment } \\
\text { (millimetres) }\end{array}$ & $\begin{array}{l}\text { Depressed fragment } \\
\text { (millimetres) }\end{array}$ \\
\hline Standard radiography & 3.8 & 12.4 \\
Biplanar tomography & 6.5 & 15.5 \\
$\begin{array}{l}\text { Biplanar tomography with } \\
\text { 15\% correction }\end{array}$ & 5.5 & 13.2 \\
CT scanning & 5.1 & 13.0 \\
\hline
\end{tabular}

displacement of more than $0.5 \mathrm{~cm}$ of the split or depressed fragment as seen on plain radiographs demanded surgical intervention.

The anatomy of the tibial plateau is complex and restoration of its morphology is, in our opinion, important for normal knee movement. This is particularly true if the demands made on the knee are great, as abnormal loading may result in the early onset of degenerative changes. The extent of plateau involvement, as well as the displacement and comminution of both the plateau and the supporting cortex, are factors that need to be assessed against the background of the individual's age and the likely demands on the injured knee. Adequate initial assessment of such a fracture is therefore essential.

Standard radiographs can be misleading because of the $105^{\circ}$ slope of the tibial plateau. Although the oblique view may provide more accurate radiographic measurement of the depression (Moore and Harvey 1974), it has the same drawbacks as a plain radiograph in that the anterior and posterior aspects of the tibia are magnified by different amounts, and the exact area of plateau involvement in the fracture remains unclear.

Biplanar tomograms, if arranged in sequence and carefully studied, provide adequate information about the type and extent of the fracture; and if a magnification factor of $15 \%$ is taken into account, they also provide some information about the magnitude of displacement. However, all the splints have to be removed and the patient given adequate analgesia before beginning this investigation. Although in our study an average of 15 exposures in two planes was taken, the exact extent of the fractures and the degree of cortical comminution was still difficult to appreciate.

Computerised axial tomograms, however, can be carried out in the presence of splints and, indeed, through plaster of Paris, without inconveniencing the patient to any great extent. The transverse sections obtained in this way provided a graphic picture of the exact location and extent of plateau involvement; thus classification of the fractures was easier, the magnitude of displacement of the split or depressed fragment was easily documented, and the site and extent of cortical comminution was well demonstrated. This facilitated decisions about operative management, especially with regard to the portal through which a depressed segment 
of the plateau might be elevated, and whether a buttress plate might be needed. Two of the 16 fractures studied had such extensive comminution that the decision to operate, based on plain radiographs and biplanar tomograms, was rescinded and early mobilisation as advocated by Apley (1956) instituted instead.

In conclusion, although the information obtained from biplanar tomography is of value if the tomograms are viewed carefully and in sequence, computerised axial tomograms offer a clearer picture of the fractured tibial plateau and the extent of cortical comminution; they are also easier to read and to measure. In our opinion, where standard radiographs in two planes are considered inadequate, CT scanning provides the necessary information for pre-operative planning with less discomfort to the injured patient. It also provides, for possible long-term study, more accurate knowledge of the anatomy of this difficult fracture.

\section{REFERENCES}

Apley AG. Fractures of the lateral tibial condyle treated by skeletal traction and early mobilisation: a review of sixty cases with special reference to the long-term results. $J$ Bone Joint Surg $[\mathrm{Br}]$ $1956 ; 38-B$ : $699-708$.

Duparc J, Ficat P. Fractures articulaires de l'extrémité supérieure du tibia. Rev Chir Orthop 1960;46:339-486.

Elstrom J, Pankovich AM, Sassoon H, Rodriquez J. The use of tomography in the assessment of fractures of the tibial plateau. $J$ Bone Joint Surg [Am] 1976;58-A :551-5.

Hohl M. Tibial condylar fractures. J Bone Joint Surg [Am] 1967;49-A:1455-67.

Moore TM, Harvey JP Jr. Roentgenographic measurement of tibialplateau depression due to fracture. J Bone Joint Surg [Am] $1974 ; 56-A: 155-60$.

Rasmussen PS. Tibial condylar fractures: impairment of knee joint stability as an indication for surgical treatment. J Bone Joint Surg [Am] 1973;55-A:1331-50.

Rombold C. Depressed fractures of the tibial plateau: treatment with rigid internal fixation and early mobilization: a preliminary report. J Bone Joint Surg [Am] 1960;42-A :783-97. 